\title{
Diagnosis | Esophageal stenosis with a secondary fistula
}

The rat died of complications arising from an esophageal stenosis or stricture that prevented the passage of food and water (Fig.4). A large mass formed as result of a fistula in the esophageal wall, directing the food towards a thoracic sac instead of the stomach. There are several possible mechanisms to explain the triggering of these events.

Cases of congenital esophageal stenosis have been reported in humans ${ }^{1-3}$, horses ${ }^{4}$, cats and $\operatorname{dog} 5^{5,6}$. Therefore, our rat may have had this abnormality from birth, although not sufficiently severe to prevent the complete passage of maternal milk or small quantities of food. As the rat grew, the stricture remained, keeping the esophageal lumen smaller than normal. This abnormality produced food impaction in the esophagus up to the point of the stricture; with increased food pressure and/or irritation of the esophageal mucosa, a fistula formed in the wall of the esophagus and the food started building up in the sac. The growing sac then compressed the lungs, which caused dyspnea and exacerbated the stenosis. The fistula could once have had a direct connection to the esophagus to allow the passage of food remnants, but given the fact that we did not observe a direct link between the esophagus and the sac at necropsy, we suggest that the connection eventually closed. Although it is possible that a very small area remained open, we were unable to detect it without microscopic examination of the esophagus-fistula junction.

A second possibility involves the development of choke by the gradual accumulation of food that failed to pass through the esophagus ${ }^{7,8}$. In humans, this pathology is associated with esophageal scarring and stricture resulting from chronic gastroesophageal reflux ${ }^{9}$. However, rats cannot vomit, but rather display pica behavior (i.e., consumption of nonnutritive substances) under circumstances that induce vomiting in other species ${ }^{10-13}$. Consequently, it is possible that the esophageal irritation caused nausea in the female rat, which contributed to the deterioration

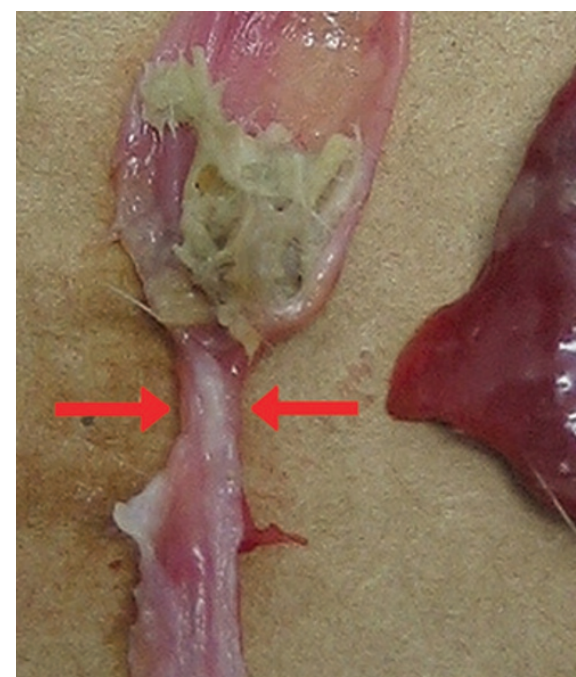

FIGURE 4 | Esophageal stricture at the junction of the esophagus and the mass in Figure 3. Notice the impaction of food before the stricture.

of its condition because it consumed food and/or beta chips, facilitating compaction and formation of the fistula. Interestingly, enrofloxacin has been reported to induce adverse gastrointestinal reactions including vomiting in dogs ${ }^{14}$. Therefore, it is also possible that the enrofloxacin injected after surgery and during the treatment may have induced nausea and pica, worsening the rat's condition even further.

Esophageal stenosis is diagnosed in humans through fluoroscopic esophagography and endoscopic exploration. Spontaneous or congenital esophageal stenosis is rare in laboratory rats, and the definitive diagnosis may be restricted to necropsy. Excessive salivation and loss of weight are clinical signs that may suggest an obstruction of the upper digestive tract. If esophageal stenosis is suspected in rats, treatment should not include drugs with side effects that may induce nausea in other animals (e.g., buprenorphine ${ }^{8}$ ) due to the potential induction of pica in rats.

Esophageal strictures are treated in dogs and cats with balloon dilation or esophageal bougienage ${ }^{5}$. Most patients become functional, although dietary change may be necessary. Post-dilation therapy in cats and dogs consists of administration of cimetidine, metoclopramide, sucralfate, and prednisone $e^{6}$. Experimentally induced benign esophageal stenosis in rats has been treated with balloon catheter dilation. Researchers report an increase in the cross-sectional areas and perimeters of all esophageal layers ${ }^{15}$.

1. Katzka, D.A. et al. Congenital esophageal stenosis in adults. Am. J. Gastroenterol. 95(1), 32-36 (2000).

2. Zhao, L.L., Hsieh, W.S. \& Hsu, W.M. Congenital esophageal stenosis owing to ectopic tracheobronchial remnants. J. Pediatr. Surg. 39(8), 1183-1187 (2004).

3. Machmouchi, M.A., Al Harbi, M., Bakhsh, K.A. \& Al Shareef, Z.H. Congenital esophageal stenosis. Saudi Med. J. 25(5), 648-650 (2004).

4. Clabough, D.L., Roberts, M.C. \& Robertson, I. Probable congenital esophageal stenosis in a thoroughbred foal. J. Am. Vet. Med. Assoc. 199(4), 483-485 (1991).

5. Sellon, R.K. \& Willard, M.D. Esophagitis and esophageal strictures. Vet. Clin North Am. Small Anim. Pract. 33(5), 945-967 (2003).

6. Leib, M.S. et al. Endoscopic balloon dilation of benign esophageal strictures in dogs and cats. J. Vet. Intern. Med. 15(6), 547-552 (2001).

7. Jones, T.C., Hunt, R.D. \& King, N.W. Veterinary Pathology 6th Edn. (Lippincott Williams \& Wilkins, Baltimore, MD, 1997).

8. Ovadia, S. \& Zeiss, C.J. What's your diagnosis? Ptyalism and anorexia in a Sprague-Dawley rat. Lab Anim. (NY) 31(9), 25-27 (2002).

9. Bremner, C.G. Benign strictures of the esophagus. Curr. Probl. Surg. 19(8), 401-489 (1982).

10. Mitchell, D., Krusemark, M.L. \& Hafner, D. Pica: a species relevant behavioural assay of motion sickness in the rat. Physiol. Behav. 18(1), 125-130 (1977).

11. McCaffrey, R.J. Appropriateness of kaolin consumption as an index of motion sickness in the rat. Physiol. Behav. 35(2), 151-156 (1985).

12. Liu, Y.L., Malik, N., Sanger, G.J., Friedman, M.I. \& Andrews, P.L. Pica-a model of nausea? Species differences in response to cisplatin. Physiol. Behav. 85(3), 271-277 (2005).

13. Mitchell, D., Laycock, J.D. \& Stephens, W.F. Motion sickness-induced pica in the rat. Am. J. Clin. Nutr. 30(2), 147-150 (1977).

14. Altreuther, P. Safety and tolerence of enrofloxacin in dogs and cats. Proc. $1^{\text {st }}$ Int. Symp. On Baytril, 15-19 (1992).

15. Cheng, Y.S. et al. Restenosis following balloon dilation of benign esophageal stenosis. World $\mathrm{J}$. Gasteroenterol. 9(11), 2605-2608 (2003). 